\title{
LA DIGNIDAD DEL "VIEJO VIEJO"
}

Bernard N. Schumacher*

RESUMEN: En las sociedades actuales se propone una imagen de "viejo joven", siempre y cuando pueda costear el management racional para un envejecimiento exitoso; en caso contrario, el horror -tanto económico como simbólico-que el "viejo viejo" despierta en una sociedad sana y eficiente, como espejo futuro, orilla a su sistemática discriminación. Sin embargo, una de las acepciones de dignidad refiere a su valor intrínseco. Por ello, cuidar del "viejo viejo" es la apuesta de una política humanista en una sociedad responsable.

$$
\text { sose }
$$

ABSTRACT: In our current society, an image of "young old man" is suggested as long as one can finance the rational management for a successful aging process. When this is not the case, the horror both economic and symbolic that the "old old man" causes in a healthy and efficient society as an image of their own future, triggers a systematic discrimination. However, one of the definitions of dignity refers to its intrinsic value. Therefore, caring for the "old old man" is the position of a humanistic policy from a responsible society.

PALABRAS CLAVE: bioética, dignidad, viejo-viejo, viejo-joven, política humanista. KEY WORDS: bioethics, dignity, old-old, old-young, humanistic policy.

RECEPCIÓN: 22 de enero de 2013.

APROBACIÓN: 14 de mayo de 2013.

*Universidad de Friburgo, Suiza. 
CITAM Derechos Reservados.

La reproducción total o parcial de este artículo se podrá hacer si el ITAM otorga la autorización previamente por escrito. 


\section{LA DIGNIDAD DEL "VIEJO VIEJO"*}

${ }^{66}$ La cultura misma, la cultura en general, es esencialmente, ante todo, digamos incluso a priori, cultura de la muerte. Y por consiguiente historia de la muerte". ${ }^{1}$ Esta cita del filósofo francés Jacques Derrida subraya el hecho de que la actitud del ser humano hacia la muerte, y la manera como la entiende, se percibe especialmente en la cultura que baña el mundo dentro del cual vivimos; el hecho de que pensemos en qué forma mueren nuestros contemporáneos en Occidente; en la forma que concebimos el lugar de su muerte (ya sea en casa o, lo más seguido, en una institución médica); en las condiciones en las cuales mueren (solos, abandonados, acompañados por parientes o profesionales, de manera "natural", después de una obstinación poco razonable, por eutanasia o lo que llamamos “auto-liberación"); en la manera en la que les rendimos un último homenaje; en la manera en la que vivimos su duelo; en la manera en la que concebimos sus sepulturas; finalmente, en la manera en la que tratamos a los difuntos (culto a los antepasados, memoria simbólica). La cultura de la muerte se basa, igualmente, en la cultura de la enfermedad, en tanto que manifestación de la deficiencia, de la vulnerabilidad y del eventual morir. En otros términos, para retomar una expresión de Derrida, "toda cultura significa un tratado o tratamiento de la muerte"; ${ }^{2}$ dicho de otra manera, informa sobre cómo el ser

* Traducción de Maiala Meza.

${ }^{1}$ Jacques Derrida, Apories. Mourir-S'attendre aux "limites de la vérité", 1996, Paris, Galilée, p. 83.

${ }^{2}$ Ibid., p. 84. 
humano enfrenta a la muerte, ya sea negándola, huyéndola o asumiéndola. ${ }^{3}$ Esta afirmación también valdría para la cultura de la enfermedad, para la de la persona discapacitada mental, para la de los últimos instantes de la vida o de la vejez -momento por excelencia de la consciencia de la mortalidad como manifestación empíricamente constatable de la vulnerabilidad humana. El otro, frágil y deficiente; el otro, dependiente en la vejez, es especialmente el signo anunciador de la muerte por llegar y de la mortalidad. En breve, para el que goza de buena salud, es el reflejo de lo que es: vulnerable, frágil, mortal e intrínsecamente dependiente del prójimo. Por lo tanto, ¿cómo caracterizar la cultura contemporánea de la muerte en Occidente, y particularmente la cultura de la vejez, en tanto que cultura de la persona debilitada y deficiente?

El envejecimiento conduce inexorablemente no sólo al proceso de morir y a final de cuentas al deceso, sino que también implica una lenta degradación del ejercicio de la autonomía, del discernimiento, del consentimiento llamado "iluminado", de la toma de decisión. En última instancia, ¿la vejez no contraviene la dignidad, cuando no la fagocita? ¿No podemos considerar esta última etapa de la vida-como por otra parte toda vida humana que se encuentra en una situación análogacomo indigna?

10 Para intentar contestar a estas preguntas, me propongo abordar en primer lugar el tema de la vejez y de su estatus en el seno de la sociedad contemporánea occidental, lo que implica tratar igualmente los estatus de las personas fragilizadas y en situación de deficiencia física y mental. A continuación, diferenciaré varias maneras de entender la dignidad que aplico a la vejez, para finalmente cuestionar el lugar y el estatus del anciano en el seno de la ciudad.

\section{La vejez}

La cultura predominante de la sociedad contemporánea occidental eleva al rango de valores supremos el rendimiento, el dominio, el control, la eficacia, la rentabilidad y la independencia. Estos valores también

${ }^{3}$ Véase Françoise Dastur, Comment affronter la mort?, 2005, Paris, Payard; Bernard N. Schumacher, Confrontations avec la mort, 2005, Paris, Cerf. 
impregnaron tanto el mundo del trabajo, ${ }^{4}$ de la educación, ${ }^{5}$ de la economía, de la medicina y de la asistencia médica, como la existencia cotidiana, incluido el proceso de duelo y del envejecimiento. El duelo se convierte en un asunto que se debe dominar con el fin de neutralizar los efectos negativos y desestabilizadores que podrían tener sobre su propia vida la muerte del ser querido, la cual le recordaría la omnipresencia de la muerte. El duelo se percibe como una especie de trabajo que hay que administrar lo más eficazmente posible: hay que "hacer" el duelo. Por otra parte, el imperativo de ser lo menos visible que se pueda para los otros; hay que ser discreto, so pena de indisponer; el duelo arriesgaría desestabilizar al otro y lo obligaría a confrontarse con su finitud vulnerable, con su propia muerte. Del mismo modo, se ha vuelto una obligación borrar toda huella de envejecimiento, expresión ineluctable de la muerte. Los actuales baby-boomers que se jubilan, libres de toda carga familiar y de responsabilidades profesionales, imperativamente, deben "sacar adelante" su jubilación, es decir, su vejez, administrarla lo más eficazmente posible, dominarla, volverse "maestro y poseedor", ${ }^{6}$ retomando una expresión de René Descartes. El bioquímico y escritor Joël de Rosnay, que está convencido de ello, afirma lo que sigue: “es posible vivir la última fase de nuestra vida, lograr nuestra longevidad. Prolongar la duración de la vejez o prolongar la de la juventud no es lo mismo para nada: es más positivo tratar de alargar la duración de la juventud. Envejecer 'joven' en cierta forma". ${ }^{7}$ Se trata de establecer "reglas racionales de management de nuestro cuerpo [...] de successful ageing (envejecimiento exitoso)". ${ }^{8}$

${ }^{4}$ Véase al respecto el reportaje titulado Les Blues du facteur en el programa "Temps présent", Télévision Suisse Romande, la 1 ${ }^{\text {era }}, 15$ de diciembre de 2011 y la célebre película de Jacques Tati, Jour de fête (1949).

${ }^{5}$ Véase Martha Nussbaum, Les Émotions démocratiques. Comment former le citoyen $d u$ XXIe siècle, 2011, Paris, Climats (Flammarion), trad. al francés por Solange Chavel; Not for Profit. Why Democracy Needs the Humanities, Princeton, Princeton University Press, 2010.

${ }^{6}$ René Descartes, Discours de la Méthode, 2000, París, Flammarion, VI, p. 99.

${ }^{7}$ Joël de Rosnay, J. L. Servan-Schreiber, F. de Closets et D. Simmonet, Une vie en plus, la longevité pourquoi faire?, 2005, Paris, Seuil, p. 43.

${ }^{8}$ Ibid., p. 44. Dominique Simonnet exclama: "Es un regalo fabuloso el que acabamos de recibir: ¡una vida extra! De quince a veinte año de bono, de pronto, de ventaja, regalado a las poblaciones de los países acomodados del planeta. Mejor: podemos consumir ese suplemento de existencia con buena salud e incluso en plena forma”, ibid., p. 11. 
Esta exigencia de maestría del desempeño y de la eficacia, que encuentra su ideal en la juventud, desemboca en el imperativo de parecer joven -incluso hacia sí mismo- el mayor tiempo posible, de envejecer sin volverse viejo, resumiendo: ser un "viejo joven". El envejecimiento ya no se percibe como un simple proceso natural, al cual habría que someterse pasivamente, un proceso que se trata de dejar pasar, sino como un "objeto" de control en vista de prolongar la esperanza de vida -la cual, por otro lado, se ha duplicado en un siglo en el mundo occidental-; la noción de envejecimiento es la imagen que le presentamos al prójimo y a nosotros mismos.

El management del envejecimiento se concentra, en un primer momento, sobre aquello que aparece de la manera más evidente, a saber, el cuerpo. Éste se entiende cada vez más como un objeto que la técnica puede modelar y, si se trata de luchar contra él, es principalmente por miedo a la muerte. ${ }^{9}$ Lo vestimos joven; le damos a escuchar músicas jóvenes; viajamos joven; hacemos el amor joven gracias al viagra. Cuidamos nuestro cuerpo a nivel cosmético, deportivo (fitness) y dietético, pero también a nivel del ejercicio de las facultades mentales, entre ellas la memoria. Por ejemplo, invertimos en la medicina anti-edad, como lo demostró recientemente el médico Jean-Claude Houdret, quien publicó en colaboración con el célebre estilista Karl Lagerfeld una obra sobre la pérdida de peso y el bienestar. ${ }^{10}$ La meta: no parecer de su edad, aparecer todavía y siempre como un "viejo joven" en la "sociedad del espectáculo" que es la nuestra, retomando el título de la famosa obra de Guy Debord. ${ }^{11}$ Esta euforia de la juventud que se expresa en el fantasma de la eterna juventud, reforzada por el mito del progreso infinito de los avances tecnológicos, ${ }^{12}$ no sólo es valorada como modelo de logro y de desempeño en vista del bienestar y de una existencia realizada: responsables ciudadanos lo vuelven asimismo

${ }^{9}$ Véase David Le Breton, L'Adieu au corps, 1999, Paris, Métaillé.

${ }^{10}$ Véase Karl Lagerfeld y Jean-Claude Houdret, Le Meilleur des régimes, 2010, Paris, Laffont.

${ }^{11}$ Véase Guy Debord, La Société du spectacle, 1996, Paris, Gallimard, retomado en Cuvres, 2006, Paris, Gallimard, pp. 766-873.

${ }^{12}$ Véase David Le Breton, "Le corps insuffisant. La quête contemporaine d'immortalité", en Frédéric Lenoir y Jean-Philippe de Tonnac (eds.), La Mort et l'Immortalité, 2004, Paris, Bayard, pp. 998-1009. Francis Fukuyama, La Fin de l'homme. Les Conséquences de la révolution biotechnique, 2007, Paris, Gallimard, trad. al francés por Denis-Armand Canal. 
obligatorio, de manera sutil, y podríamos añadir, tiránica. Es hacer obra de ciudadanía tomar conciencia, seriamente, de la responsabilidad hacia la sociedad, no sólo en cuanto a la clasificación de la basura y a la preservación del ecosistema, sino también, y particularmente, en cuanto al imperativo del bien envejecer, es decir, del hecho de envejecer en condiciones satisfactorias de salud física y mental. La razón es simple: no depender del otro, no ser una carga afectiva y menos financiera, para la sociedad que debe preocuparse ante todo por la construcción del porvenir. El período existencial de la vejez debe ser asumido por la esfera de la rentabilidad, a saber, por la exigencia del dominio eficaz de los costos: obtener el máximo haciendo los menores gastos posibles. Desde entonces, es un deber moral vivir dignamente la vejez, con la condición siempre de ser eficaz: estar sano y no costarle a la sociedad; es muestra de egoísmo no someterse a la imposición del nuevo management de la vejez.

Aunque empujado a lograr su vejez jugando al "viejo joven", el baby-boomer, sin embargo, se encuentra un buen día, inevitablemente, frente a lo ineluctable, sin haber sido preparado: la toma de conciencia del paso al estatus de "viejo viejo". La mala fe y la máscara de la apariencia, disfraces del dominio de la muerte, por medio de la tiranía social de la euforia de la juventud, dan lugar, más o menos repentinamente, a la conciencia de la desnudez del ser frágil y dependiente; se le propone asumir su condición mortal. ${ }^{13}$ Se puede decir de esos babyboomers, siguiendo a Séneca, que "su espíritu es aún pueril, cuando los agobia la vejez, a donde llegan sorprendidos y desarmados; puesto que nada está previsto, cayeron bruscamente sin darse cuenta; no la sintieron venir cotidianamente". ${ }^{14} \mathrm{El}$ estoico describe maravillosa-

13 "Este abismo que actualmente separa dos continentes y opone desde ahora las primeras edades a las últimas, entre el sentimiento de toda potencia de unos y el sentimiento de vulnerabilidad de otros, el egocentrismo triunfante de la juventud y el clima de depresión de la vejez - puesto que que ya no es para nada el viejo de antes que envejece, sino un joven contemporáneo, educado en el sentimiento de que 'no está cerca de suceder', que tendríamos mucho tiempo para pensarlo, un joven que ha debido cargar el yo hipertrofiado que las circunstancias de la mortalidad lo han forzado a proteger y que absolutamente no está preparado para envejecer", Paul Yonnet, Le Recul de la mort. L'Avènement de l'individu contemporain, 2006, Paris, Gallimard, p. 231.

${ }^{14}$ Sen., Dial., IX, 4 (La Brièveté de la vie, 1980, Paris, Les Belles Lettres, trad. al francés por Abel Bourgery, p. 59). 
mente este difícil despertar de la toma de conciencia de la propia vejez, el desgarro del velo de la ilusión, en el cual el ser humano contemporáneo se complace, refugiándose en una actitud de inautenticidad que se expresa mediante el uno muere, en vez del uno envejece. El mismo Séneca tenía más de 65 años, edad muy respetable en relación con la esperanza de vida de la época, cuando escribió la décimo segunda carta a Lucilio:

Por doquiera que me vuelvo, veo las pruebas de mi senectud. Había venido a mi villa suburbana y me quejaba de los gastos provocados por la persistente degradación del edificio. El administrador me manifestó que los defectos no provenían de negligencia suya alguna: todo lo necesario se hacía, pero la villa estaba ya vetusta. Esa villa había crecido entre mis manos: ¿qué depara para mí el futuro si en tan ruinoso estado están aquellas piedras que mi edad comparten? Irritado, aproveché la primera ocasión para increparlo: "Es evidente que aquellos plátanos han sido descuidados" -le dije- "No tienen follaje alguno. ¡Cuán nudosas, cuán retorcidas sus ramas, cuán tristes y escuálidos están sus troncos! ¡Tal cosa no hubiera sucedido si los hubieres circundado de canteros, si los hubieras regado! Aquél juró por mi genio que todo hacía, que en nada omitía sus cuidados, pero que estaban ya avejentados. Entre nosotros: soy yo mismo quien los había plantado, soy yo mismo, quien por la primera vez contemplé su follaje. Me torné hacia el pórtico: “quién es ese decrépito?” -pregunté- "con razón es llevado a la entrada. Ya mira para el otro lado. ¿De dónde lo sacaron? ¿Te deleitas acaso en rejuntar los muertos de los otros?” Este respondió: “¿Acaso no me reconoces? Soy yo, Felicio, tu pequeñuelo, tu favorito, a quien solías regalar estatuillas, soy el hijo de tu mayordomo Filostio". "Delira totalmente" -me dije- "¡Helo allí hecho un chicuelo y por añadidura mi preferido! Puede que así sea: ¡por lo pronto ya se le caen los dientes! Debo eso a mi villa suburbana: que hacia cualquier lado que me volviera, se aparecía mi senectud. Abracémosla, amémosla, plena es de goces si sabes utilizarla. ${ }^{15}$

Séneca, como Cicerón, exalta las ventajas de la vejez que hay que recibir con los brazos abiertos. Las grandes acciones no son realizadas, según Cicerón, "por el vigor, la agilidad o la rapidez corpo-

${ }^{15}$ Sen., Ep., 12, 1-4 (Lettres à Lucilius, tomo I, 1985, Paris, Les Belles Lettres, trad. al francés por Henri Noblot, pp. 39-40). 
rales”, sino más bien “por la sabiduría, la autoridad y el valor de las opiniones; y lejos de ser privada de ellos, la vejez generalmente tiene más". ${ }^{16}$ Incluso, a medida que se avanza en edad y que se envejece, precisa, liberados del yugo del placer y de la pasión, es al goce del pensamiento que se accede: "se ha de estar inmensamente agradecidos a la vejez que se encarga de que no gocemos de lo que no nos conviene. En efecto, el placer impide la reflexión, es enemigo de la razón, de la mente. Ofusca, por así decirlo, los ojos del alma, y no tiene ninguna relación con la virtud". ${ }^{17}$

Estas descripciones de la vejez tal vez son ciertas para el actual baby-boomer que alcanzó ya la tercera edad. No sucede lo mismo con la persona propulsada a la cuarta edad, consciente del declive progresivo, a la vez radical e irreversible, de sus fuerzas mentales y físicas, que desembocará inexorablemente en la muerte.

La bajada es continua -precisa el filósofo italiano Noberto Bobbio, entonces de 91 años-, y lo que es peor, irreversible: bajas cada vez un pequeño escalón, pero una vez puesto el pie en el escalón inferior, sabes que no volverás al escalón superior. Todavía no sé cuántos hay. Sin embargo, hay una cosa de la que no puedo dudar: cada vez hay menos. ${ }^{18}$

Esta bajada inexorable está acompañada de la lentitud creciente al emprender incluso hasta las más básicas actividades físicas y mentales. La vida del "viejo viejo", tanto a nivel del cuerpo como del pensamiento, se desarrolla en cierta forma al ralentí; sin embargo, el tiempo que le queda por vivir debe ser tomado en cuenta:

La lentitud del viejo - precisa Bobbio- [...] es pesada para sí y para la mirada de los otros. Suscita más lástima que compasión. El viejo está, por naturaleza, destinado a quedarse atrás, mientras que los demás van adelante. Se detiene. Se sienta en un banco. Necesita un poco de descanso.

${ }^{16}$ Cic., Sen., VI, 17 (De la vieillesse, 2008, Paris, Les Belles Lettres, trad. al francés por Pierre Wuilleumier.

${ }^{17}$ Ibid., XII, 42.

${ }^{18}$ Noberto Bobbio, “Au ralenti. Vieillesse, mémoire, mort”, en Le Sage et la Politique. Écrits moraux sur la vieillesse et la douceur, 2004, Paris, Albin Michel, trad. al francés por Pierre-Emmanuel Dauzat y Denis Trierweiler, pp. 122-3. 
Los que estaban atrás lo alcanzan, lo rebasan. Le gustaría apresurar el paso, pero no lo logra. Cuando habla, buscando sus palabras, se le escucha sin duda con respeto, pero no sin signo de impaciencia. Las ideas también tardan más en salir de la cabeza. Las que salen son a menudo las mismas. ¡Qué fastidio! [...] Mientras que el ritmo de la vida del viejo es cada vez más lento, el tiempo que tiene ante él se reduce cada día. [...] Necesito más tiempo y cada vez tengo menos. ${ }^{19}$

El “viejo viejo" se caracteriza, asimismo, por una soledad y una marginalización crecientes, un sentimiento de extrañeza en relación con el mundo y la sociedad; se siente relegado a la categoría de los has been, definitivamente privado del estatus de héroe de lo antiguo que prevalecía bajo la pluma de Séneca y de Cicerón. El escritor François Mauriac, lúcido, precisa a los 80 años (años antes de su muerte) que cuando éramos jóvenes:

poseíamos ese pasaporte que legitima en todos lados una joven presencia. No es que hoy le pidan a uno sus papeles. No vale la pena: sabemos que usted es un extranjero, sólo hay que verlo, puesto que usted es viejo - un extranjero venido de otro mundo, lleno de los recuerdos de un viaje que nadie tiene ganas de conocer. Incluso el lenguaje es otro y sobre todo el movimiento de la vida: aunque un viejo corazón no lata más lento que uno joven, el desacuerdo profundo se debe a una oposición de ritmo. ${ }^{20}$

El "viejo viejo" ya no es considerado, como lo afirmaban los filósofos de la antigüedad, como aquel que transmite la tradición y la cultura, el saber-hacer, la moral, la sabiduría; aquel que ostenta el poder o que encarna el "bien-vivir", en el sentido de una vida que el ejercicio de las virtudes ha cumplido. El "viejo viejo" se caracteriza

${ }^{19}$ Ibid., pp. 141-2; 145-6.

${ }^{20} \mathrm{Y}$ precisar, justo antes de esta cita, que el viejo hombre permanece idéntico al hombre que era: "Tal como todavía estamos aquí, la puerta de nuestra habitación cerrada, ya no somos vistos, es decir, ya no interpretados. Tal como estamos, tal como siempre fuimos. Puesto que de esto estamos seguros, nosotros que nos conocemos desde dentro: no diferimos en nada, a esta hora de la decadencia, del ser humano que manifestaba por fuera una mirada brillante y cuya mecha negra sombreaba la frente”, François Mauriac, Mémoires intérieurs. Nouveaux Mémoires intérieurs, 1985, Paris, Flammarion, pp. 420-1. 
más bien por una ignorancia cada vez más grande, ante la evolución extremadamente rápida de las tecnologías y de las perpetuas mutaciones que marcan la vida contemporánea, lo que resulta en un aislamiento social, incluso en una muerte social, en una sociedad sometida a la tiranía de la productividad, del desempeño y de la eficacia para sí misma. La sabiduría del "viejo viejo" es percibida como inútil y superficial por una sociedad que se interesa casi exclusivamente en el conocimiento instrumental, es decir, el que es útil. A fin de cuentas, la vejez trae consigo la disminución, incluso la pérdida del ejercicio de las facultades de la reflexión, del discernimiento y de la autonomía. Incluso podemos llegar a decir que esta decadencia de la voluntad, esta decadencia física e intelectual en la cual se encuentra clavado el "viejo viejo", aparece como "una desgracia", con la cual nosotros, en buen estado de salud, no tenemos nada que ver. ${ }^{21}$ La sociedad, convencida de la juventud, pone todos los medios para desviar nuestra mirada de los "viejos viejos", por miedo a que los concibamos, profundamente, como nuestros semejantes.

Desde entonces, en el seno de la sociedad occidental la vejez se percibe, cada vez más, como una carga cotidiana para los sanos, los activos, los competitivos, los eficaces. Para deshacerse de ella y no verla de frente, como en un espejo que nos regresaría nuestra propia imagen, simplemente la desaparecemos en un no man's land en nombre del principio out of sight, out of mind, out of reality; por otra parte, lo mismo se hace con el gran tabú de la muerte, sometida a un proceso de desimbolización y desmitificación en la esfera pública y social, de la misma manera que suprimimos todo aquello que nos la recuerda. El "viejo viejo" es excluido progresivamente, apartado de la sociedad de las personas autónomas y competentes. El rechazo y la negación de la muerte se expresan, sobre todo, en la actitud de los sanos, a quienes les cuesta mucho encontrar tiempo para consagrar a los "viejos viejos", como les cuesta también proporcionarles un espacio completo de la sociedad en el seno de la comunidad de personas. Son la imagen de su vulnerabilidad y de su muerte por venir. Los has been se alojan más en guetos; por otro lado, las personas en situación de gran minusvalía

${ }^{21}$ Simone de Beauvoir, La Vieillesse. Essai, 1970, Paris, Gallimard, p. 11. 
mental padecen la tentativa de expulsión de la memoria de los productivos saludables. A menudo, su existencia es menospreciada, considerada superflua, estigmatizada al punto que se comienza a escuchar a personas sanas decir que aquéllos constituyen una carga financiera para la sociedad, que son parásitos, "pesos muertos", incluso freno para la producción y el desarrollo del progreso para las generaciones futuras; que el aumento en las primas de los seguros médicos se debe, principalmente, a los últimos años de los "viejos viejos" y a la tendencia que consiste en emprender de todo para mantenerlos con vida. Si aún son grandes consumidores, es de fondos públicos. "Protegida tras los mitos de la expansión y de la abundancia", constata en 1970 Simone de Beauvoir, la sociedad occidental, ganada por la carrera del provecho, "trata a los ancianos de parias", como "desechos", "escoria", "cadáveres ambulantes". ${ }^{22}$ Jean Baudrillard señala unos años más tarde, en 1976, que para la sociedad occidental competente:

La tercera edad [hoy hay que hablar de una cuarta edad] se convierte en un peso muerto considerable en la gestión social. Toda una parte de la riqueza social (dinero y valores morales) es tragada sin poderle dar un sentido. De esta manera, un tercio de la sociedad es puesto en estado de parasitismo económico y de segregación [...] La Tercera Edad bien dice lo que quiere decir: es una especie de Tercer Mundo. No es más que un trozo de vida, marginal, asocial al límite - un gueto, una condena condicional, un glacis de antes de la muerte. Es propiamente la liquidación de la vejez. A medida que los vivos viven más tiempo, a medida que "ganan" sobre la muerte, dejan de ser reconocidos simbólicamente. Condenada a una muerte que siempre retrocede, esta edad pierde su estatus y sus prerrogativas. En otras formaciones sociales, la vejez existe realmente, como pivote simbólico del grupo. El estatus del anciano, que da el último toque de antepasado, es el más prestigioso. Los "años" son una riqueza real que se intercambia con autoridad, con poder, mientras que hoy los años "ganados" sólo son años contables, acumulados sin poder de intercambio. La esperanza de vida prolongada sólo desembocó en una discriminación de la vejez: y esta discriminación, lógicamente, deriva en la discriminación de la muerte misma. ${ }^{23}$

${ }^{22}$ Ibid., pp. 8, 12, 568, 13.

${ }^{23}$ Jean Baudrillard, L'Échange symbolique et la Mort, 1976, Paris, Gallimard, pp. 249-50. Axel Kahn precisa, más de treinta años después, que "la naturaleza económica y social de nuestro 
La vejez, como toda persona en situación de deficiencia mental o al final de su vida, amenaza crecientemente a una sociedad que no deja de promover la productividad, el beneficio, la eficacia y la juventud. El "viejo viejo" es descalificado, puesto fuera del juego de alguna manera, al margen de los que están sanos: ya no puede hacer la finta y engañar a las apariencias. Es estigmatizado como inútil, un parásito viviendo a expensas de los sanos. Podríamos incluso llegar a sostener la emergencia de una fobia del "viejo viejo", vuelto ineficaz en la deficiencia y la dependencia, la fragilidad y la vulnerabilidad. La razón de sacar del juego al "viejo viejo" reside, entre otras, en el hecho de que su presencia remite, ineludiblemente, a la pregunta por el sentido de la existencia y su deseabilidad (a fortiori, cuando esta existencia está en una situación de vulnerabilidad y de deficiencia, de no productividad). Esta cuestión está también en el corazón del reconocimiento prenatal que apunta, según Didier Sicard, médico y presidente del Comité consultivo nacional de ética en Francia (CCNE), "en una gran mayoría de casos, a la supresión y al no tratamiento" y por consiguiente a "la erradicación social" de los humanos fallecientes, considerados demasiado onerosos para la sociedad. ${ }^{24}$ Esta cuestión no es menos central en la discusión concerniente a las personas afectadas por la enfermedad de Alzheimer; según Alain Madelin, cuestan demasiado caro a la sociedad; tanto, que sugiere hacerlas desaparecer antes de que se vuelvan demasiado onerosas para la colectividad. ${ }^{25}$

modelo de vida tolera a los seniors mientras gasten su dinero para saciar las envidias y los deseos aún vivos, pero llega el momento donde esas mismas incitaciones a consumir disminuyen y después se desvanecen. El momento de la exclusión sonó, aquel en el que la comunidad considera que esos viejos o enfermos se convirtieron en peso muerto. Cambiar la mirada de una sociedad totalmente formateada por su adhesión a ese tipo de 'razón de ser' -desear, consumir, producirnecesita interrogarse lúcida y colectivamente", L'Ultime Liberté?, 2008, Paris, Plon, pp. 57-8.

${ }^{24}$ Didier Sicard, "La France au risque de l'eugénisme", Le Monde, 4 de febrero de 2007. Véase Janine Chanteur, Condamnés à mort ou condamnés à vivre? Autour de l'arrêt Perruche, 2002, Gèneve-Paris-Brussels, Factuel, y Henri Torrione, "Le Préjudice d'être né", 2006, HAVE/REAS, núm. 4, pp. 388-98.

${ }^{25}$ Véanse los propósitos de Alain Madelin relatados por Axel Kahn en el marco de la Universidad de verano 2003. Sostenía que "era importante, para evitar las pérdidas colosales ligadas al aumento de la enfermedad de Alzheimer, que la ley se preparara para evitar la prolongación de la decrepitud de este tipo de enfermedades. Según él, la sociedad no podría ni psicológica ni financieramente soportar esta nueva realidad. Los últimos seis meses de vida cuestan a veces 
La presencia del "viejo viejo" nos recuerda la profundidad de nuestra finitud, nuestra dependencia, nuestra vulnerabilidad y nuestra precariedad constitutivas, en suma, nuestra incompletud esencial, como lo decía ya Aristófanes en El Banquete de Platón. ${ }^{26}$ El frente a frente con el envejecimiento remite, como en un espejo, tanto a mi radical vulnerabilidad, como a la conciencia del declive natural de mi existencia en este mundo cuyo término es mi muerte, la cual puede sobrevenir en cualquier momento. El "viejo viejo" no es en realidad más que el reflejo de lo que soy, reduciendo a nada mis tentativas de hacer prueba de mala fe, al sostener que no soy más que un sujeto competente, autosuficiente e independiente, y que sólo una vida competente e independiente, conciente de sí y autónoma, valdría la pena de vivirse o de continuarse viviendo. La idea que sostiene este razonamiento desemboca en la afirmación de que el envejecimiento, entendido como la disminución, es decir, la pérdida de la capacidad de discernimiento, de la toma de decisión, de la autonomía y de la independencia, en realidad sólo sería un proceso de pérdida de la dignidad humana. Un tema en el corazón de nuestra sociedad occidental, y del debate en torno al ser humano en situación de vulnerabilidad, consiste en saber si la vejez -aquella que se hace presente en el "viejo viejo"- realmente corresponde a una alienación del ser humano, a la negación de su dignidad.

más caro en gastos de asistencia médica que la totalidad de la existencia, recuerda. La solución más económica de sufrimiento y de dinero sería desaparecer a todas las personas afectadas de males irreversibles antes de este periodo tan dispendioso. Hablaba en particular de los cientos de miles de personas sufriendo la enfermedad de Alzheimer", Axel Kahn, op. cit., pp. 120-1. Véase también Luc Ferry y Axel Kahn, Faut-il légaliser l'euthanasie?, 2010, Paris, Odile Jacob, p. 57. Simone de Beauvoir ponía ya sobre aviso, en 1970: "La economía está basada en el beneficio, es a él que prácticamente toda la sociedad está subordinada: sólo hay interés en el material humano en la medida en el que él retribuye. Después, lo tiramos", op. cit., p. 12. Para una reflexión antropológica y ética sobre el estatus de la persona afectada de la enfermedad de Alzheimer, véase Thierry Collaud, Le Statut de la personne démente, 2003, Fribourg, Fribourg Academic Press.

${ }^{26}$ Véase Pla., Simp., 189c (Le Banquet, 2012, Paris, Garnier Flammarion, trad. al francés por Luc Brisson, pp. 114-21. 


\section{La dignidad del ser humano}

Se usa, entre las discusiones sobre el ser humano al final de la vida, emplear un cierto número de términos, sin tomarse apenas el tiempo de definirlos: autonomía, paternalismo, discernimiento "iluminado"; lo mismo sucede con la dignidad. El uso cotidiano y frecuente de este término engendra muy a menudo una gran confusión, cuando no lo vacía de significado. Si queremos saber si la vejez del "viejo viejo" corresponde a la disminución, es decir, incluso a la negación de la dignidad humana, debemos primeramente explicitar el concepto de dignidad y de sus diferentes significados.

Una primera acepción es de orden social: la dignidad abarca el prestigio y el respeto del cual se beneficia una persona que ocupa un alto rango en la sociedad. La posición elevada que ocupa esta persona suscita un comportamiento correspondiente a su estatus social; por lo tanto, el dignatario recibe los distintivos de respeto debidos a su posición. Si pensamos en nuestros políticos elegidos y en su expectativa de gestos y palabras conforme a su posición social, una dignidad tal puede adquirirse de la misma manera como puede perderse, puesto que es relativa a las circunstancias, pero también a lo que el prójimo quiera. Si hay pérdida de dignidad, ésta corresponde a una decadencia o a una degradación del estatus social.

Una segunda acepción de dignidad remite al dominio de sí por la razón y la voluntad; es el fruto del ejercicio de ciertas cualidades morales. Ser digno significa en cierta forma estar a la altura de una situación particular, haciendo prueba de valor y de nobleza de carácter, dominándose para no dejarse hundir por el sufrimiento y sin dejar que su desconcierto se exprese. Una dignidad tal implica la idea de dominio de sí, que permite atravesar sin rechistar y con estoicismo las pruebas de la existencia, sin dejarse desestabilizar. Soportar con dignidad la vejez o la enfermedad en fase terminal significa que uno no se queja, que se sufre haciendo prueba de decencia, de pudor, de reserva y de discreción, sin importunar al otro, es decir, a la sociedad.

Existe una tercera definición de dignidad, ligada a la segunda. Corresponde a la imagen que le presentamos al prójimo y a nosotros mismos en 
función de las normas de la sociedad (y personales). No deseamos perder el aspecto, mostrar nuestra dependencia y nuestra decadencia en espectáculo, puesto que mostrar una imagen tal, tanto para sí mismo como para el otro, conlleva una molestia, un malestar, cuando no repulsión y rechazo. Hay dignidad si nuestro cuerpo y persona están presentables, según mi criterio o el de los otros. Esta dignidad puede-igual que las dos primeras-desaparecer cuando me rebajo y la imagen que tengo de mí o que otro se hace de mí ya no es decente.

El "viejo viejo", como la persona al final de vida, que se se ha vuelto frágil y dependiente - situación acompañada de soledad y desamparopuede llegar a dudar seriamente de su propia dignidad. En el plano social, hace mucho que no llena una función, lo que le permitiría tener, todavía, una cierta dignidad, íntimamente ligada al papel que ejercía en el marco de esta función. Ahora está "muerto" socialmente hablando, categoría has been desde que su papel y su función pasadas le fueron retiradas; además, se percibe como una carga social cada vez más pesada, casi un peso muerto. En el plano personal, está perdiendo o ya perdió cierto dominio de sí mismo, el ejercicio de su capacidad de discernimiento "iluminado"; se reducen su voluntad autónoma y su capacidad de elección; también experimenta la pérdida de cierto sentido de la dignidad. Finalmente, pierde la autoestima, el sentido de su propia dignidad, sin lograr una imagen de sí presentable, hacia sí mismo y hacia el otro. Desde el momento que una persona tiene el sentimiento de haber perdido su dignidad en los tres sentidos ya mencionados, su vida le parece indigna: ya no vale la pena ser vivida. Continuar viviendo es, desde ese momento, percibido como indigno. ${ }^{27}$

Sin embargo, existe un cuarto significado de la noción de dignidad, que se puede calificar de intrínseco, puesto que pertenece al ser humano por su constitución como tal, independientemente de la situación en la cual se encuentre, de su papel y de su función, del ejercicio competitivo de su racionalidad, de su discernimiento y de su autonomía; independiente de la imagen que se hace de sí o de la mirada del otro.

${ }^{27}$ Axel Kahn describe el sentimiento indigno que refleja la mirada del prójimo: "Esta dialéctica es complicada, porque si me considero indigno, es ante todo porque me siento rechazado, no veo en la mirada del otro ninguna acogida, ninguna compasión, ningún amor, ninguna atracción, ningún apetito por mí. Entonces, sin sentirme ya digno de vivir, puesto que la sociedad de los otros estableció mi indignidad, no lo puedo soportar y quiero partir", op. cit., p. 52. 
El respeto que se le debe no está fundado sobre el carácter competitivo de ciertos actos, ya sea que realcen la inteligencia, la autonomía, la moral o la función social. Un respeto tal no puede ser adquirido o perdido, puesto que el valor de un ser humano no se mide con aquello que logra, sino con aquello que es: un fin en sí mismo, único e irremplazable, que no puede ser intercambiado por otro fin, sin el cual se convertiría en un medio; se escapa a todo cálculo que busque medir la vida según criterios de utilidad. Su valor no depende de criterios subjetivos de medida de la calidad de vida ni, tampoco, como lo afirman un cierto número de autores, ${ }^{28}$ de criterios de cálculo "objetivos", que refieren a una ética de intereses. "La dignidad humana, apunta Luc Ferry, no es una cuestión cuantitativa [...]. Hay en el ser humano algo que le pasa al hombre, una trascendencia que fuerza el respeto y que merece que uno pelee por ella". ${ }^{29}$ Podemos también tomar la distinción dada por Immanuel Kant: "Aquello que tiene precio puede ser sustituido por algo equivalente; en cambio, lo que se halla por encima de todo precio y, por lo tanto, no admite nada equivalente, eso tiene una dignidad". ${ }^{30}$ El cuarto significado del término dignidad afirma que el ser humano no se puede reducir, en ningún caso, al orden de cualquier precio relativo a las circunstancias, a saber, a un simple medio en vista de otra cosa, un valor condicional en función de los intereses de los sanos o de aquello que es útil. Irremplazable, no tiene ningún equivalente.

Tenemos tendencia a confundir, en el discurso actual sobre el final de la vida, las tres primeras acepciones del término de dignidad: por un lado, restablecen un sentimiento subjetivo de la dignidad, dependiendo de la capacidad de ejercer la razón y la autonomía; de la imagen que la persona se hace de sí misma, aquella que el prójimo se hace de ella, y también de su lugar en el seno de la sociedad; por el otro, la dignidad intrínseca, que no depende del ejercicio competitivo de las capa-

${ }^{28}$ Véase, por ejemplo, Jeff MacMahen, The Ethics of Killing. Problems at the Margins of Life, 2002, Oxford, Oxford University Press; Peter Singer, Questions d'éthique pratique, 1997, Paris, Bayard, trad. al francés por Max Marcuzzi; y Michael Tooley, Abortion and Infanticide, 1983, Oxford, Oxford Clarendon Press, 1983.

${ }^{29}$ Ferry-Kahn, op. cit., p. 29.

${ }^{30}$ Immanuel Kant, Fondements de la métaphysique des mours, 1993, Paris, Librairie Générale Française, Le Livre de Poche, trad. al francés por Victor Delbos, p. 113. 
cidades de la persona, aun cuando este ejercicio sea la expresión de la dignidad. La pérdida de la dignidad social, estoica y decente, que puede ser resentida y vivida subjetivamente por el "viejo viejo", no implica la pérdida de su dignidad intrínseca. Contrariamente a las tres primeras acepciones de la dignidad, la dignidad intrínseca no está sometida a ninguna gradación; dicho de otra manera, no existen grados más o menos inferiores o superiores para caracterizarla, puesto que no hay seres humanos que sean más o menos dignos que otros. No se disminuiría ni desaparecería si la persona llegara a encontrarse en una situación de deficiencia o en estado de "viejo viejo"; incluso, el último podría afirmar que siente perdida su dignidad en el sentido de las tres primeras definiciones. La dignidad intrínseca afirma que el ser humano es un fin en sí, independiente de la ausencia de logros o de deficiencias, de su "decadencia", puesto que no tiene necesidad de servir para algo o de ser competente para asegurar su dignidad. La deficiencia del ejercicio de la autonomía y del discernimiento no conlleva una decadencia en el plano del valor intrínseco del ser humano.

Experimentamos un reconocimiento fundamental de este tipo, aquel que no tiene precio, en la afirmación "te quiero" dirigida a un verdadero amigo, a un hijo, a los padres o a la persona con la que se comparte la vida. El amor -con las variantes que son la amistad, el eros y la caridad-consiente voluntariamente en la existencia del prójimo, independientemente de su rendimiento y de su eficacia. Aprueba y magnifica el simple hecho de que el otro existe $\mathrm{y}$, podríamos añadir, continúa existiendo entre nosotros. No te quiero porque eres bello, autónomo, independiente, inteligente y competente, sino simplemente porque eres, incluido cuando eres "viejo viejo", decaído, profundamente dependiente y deficiente. ${ }^{31}$ Y Clive Staples Lewis precisa que "amar, en el absoluto, es ser vulnerable". ${ }^{32}$

El respeto debido a mi persona en nombre de mi dignidad intrínseca, no depende de mi buena voluntad, ni de aquella de un libre consentimiento entre sujetos morales, ni del desempeño de la deficiencia de mi discer-

${ }^{31}$ Véase Josef Pieper, De l'amour, 2010, París, Ad Solem, trad. al francés por Jean Granier, p. 55 ss.

${ }^{32}$ Clive Staples Lewis, Les Quatre Amours, 2005, Le Mont-Pèlerin, Éditions Raphaël, trad. al francés por Denis Ducatel y Jean-Léon Müller, p. 205. 
nimiento y de mi autonomía, es decir, del peso social que yo represento para el otro. Si fuera el caso, la dignidad de un ser humano sería relativa; se le asignaría categoría de precio; entonces, el ser humano "decaído" podría ser utilizado como un simple instrumento, un medio cualquiera si así se hubiera decidido. En cuanto a las personas que ya no fueran capaces de ejercer su autonomía y su discernimiento, y que no hubieran tomado disposiciones, las personas competentes más cercanas juzgarían su dignidad según los criterios de la utilidad y según una ética de intereses. En suma, la dignidad intrínseca del ser humano, incluido cuando se encuentra en una situación de decaimiento y dependencia, prevalece sobre la dignidad relativa, sometida al sentimiento de situaciones subjetivamente juzgada como indignas.

\section{Cuidar del "viejo viejo": apuesta de una política humanista}

Estos últimos años asistimos, en el marco del debate en torno al final de la vida y del uso que se hace del término dignidad, a un deslizamiento sutil de la noción de dignidad intrínseca, hacia una dignidad dependiente de todo un conjunto de factores llamados extrínsecos: el papel y la función social del ser humano, la percepción subjetiva de la mirada del prójimo, el ejercicio de la racionalidad, de la autonomía, de la independencia y de la relación hacia el otro. El sentimiento subjetivo de la dignidad social, estoica y decente, prevaldría sobre la dignidad intrínseca, puesto que esta última no podría invocarse con el fin de que el ser humano decaído, frágil y vulnerable, vuelva a descubrir su dignidad intrínseca, por miedo de verse acusado de adoptar una actitud paternalista, que no respetaría ni el juicio ni la autonomía del otro.

El ideal y la exigencia de eficacia del ser humano ciertamente están en el corazón de la existencia humana, puesto que el cumplimiento humano es posible por el ejercicio de la racionalidad y del juicio "iluminado", de la autonomía. No sostendríamos que una vida humana, más o menos privada del ejercicio de sus facultades, y la del "viejo viejo" ofrezcan un ejemplo significativo, que sea la expresión de la plenitud del ser humano, de su cumplimiento, en suma, de lo que 
puede ser; al contrario, el envejecimiento revela una lenta decadencia irreversible, una degeneración que desemboca ineluctablemente en la muerte. El "viejo viejo" experimenta el aprendizaje doloroso de la dependencia (mayor o menor) y de dejarse llevar, que lo obliga a contar con el otro. Un abandono confiado -como también el duelo- no es posible salvo con el apoyo y la presencia del prójimo. La vejez y el morir no son incumbencia únicamente del individuo, son profundamente sociales: el sujeto no puede vivirlos plenamente salvo acompañado, llevado por el otro.

La presencia del "viejo viejo" nos remite a la cuestión del lugar del ser humano en situación de fragilidad y de dependencia en nuestra sociedad occidental, llena de independencia y competencia, bañada por un discurso ético liberal que pone el acento sobre el ejercicio de las facultades personales y, en particular, sobre la "primicia de la libertad individual sobre todo otro valor", "libre de toda obligación". ${ }^{33}$ Desde luego, esta visión promueve al "joven viejo", mientras que escamotea y rechaza la dependencia fundamental del ser humano. Uno de los mayores desafíos actuales consiste en interrogarse sobre el lugar que la cultura otorga a la persona vulnerable y frágil; nos enfrentamos a la cuestión de saber si el "viejo viejo" continua siendo un ser humano, poseedor de una dignidad, incluso cuando ya no está en condiciones de ejercer su autonomía, de elaborar un pensamiento, un discernimiento "iluminado"; cuando su parecer no es más que una desnudez que revela su ser usado y decaído, pobre y frágil, o, como lo expresa Jean-François Mattéi: “el cuerpo humano, acabado, usado y decaído, no realza el tener, sino el ser". ${ }^{34}$

La cuestión central que nos plantea la presencia del "viejo viejo" -y de todos los estados similares en los cuales se puede encontrar el ser humano-, en el contexto de una sociedad sometida a la tiranía de la eficacia, del rendimiento y de la euforia de la juventud, es saber

${ }^{33}$ Y Jacques Attali precisa: "si no es el respeto del derecho del otro en las mismas libertades", Une brève histoire de l'avenir, 2006, Paris, Fayard, p. 16. El autor propone en esta obra una historia del porvenir de estos próximos cincuenta años, que desemboca en una hiperdemocracia como "expresión última del motor de la historia: la libertad", p. 12.

${ }^{34}$ Jean-François Mattéi, “L'expérimentation sur l'être humain”, en François-Xavier Putallaz y Bernard N. Schumacher (eds.), L'Humain et la Personne, 2008, Paris, Cerf, p. 35. 
aquello "que debería ser una sociedad para que en su vejez un hombre continúe siendo un hombre", en palabras de Simone de Beauvoir. ${ }^{35} \mathrm{Se}$ trata de sustituir la autonomía en el corazón de nuestra manera de vivir en sociedad, principio de excelencia del ser moral práctico, pero también la facultad del juicio responsable, que nos permite reconocer la vulnerabilidad y la fragilidad como expresiones de aquello que el ser humano es en lo más profundo de sí mismo: un ser dependiente. El ser humano se define simultáneamente por un cierto dominio de sí y un desgarramiento de tal dominio: un buen ejemplo es el amor que transporta a la persona "fuera de ella misma" en un movimiento de entusiasmo, de receptividad y de ausencia de dominio, que Platón llama mania. $^{36}$

Encontramos esas dos dimensiones del ser humano -la autonomía y la vulnerabilidad- por analogía, en el contexto más amplio de dos formas del pensamiento humano que son complementarias y necesarias en el marco de una existencia plenamente personal, a saber, el pensamiento instrumental, calculador, por un lado, y el pensamiento reflexivo, por otro. ${ }^{37}$ La razón instrumental y operacional, según la cual la productividad y los logros constituyen la virtud más grande, objetivo social a alcanzar, es contrabalanceada por la promoción del pensamiento reflexivo y contemplativo, que no se elabora en vista de cosa alguna, sino que posee su fin en sí mismo. La puesta a punto de actividades que no sirven "para nada" -y que por lo tanto se escapan de la planificación, de la reflexión calculada y útil-, emprendidas independientemente de todo desempeño, es decir, incluso sin ser eficaces ni rentables; en resumen, actividades que tenemos la costumbre de llamar "distracciones", permiten al ser humano trascender, sobrepasar el mundo de lo útil y del "para", para fijarse en el dominio de lo que no sirve para "nada". El ocio reve-

${ }^{35}$ Simone de Beauvoir, op. cit., p. 568. Ella responde de esta manera: "La respuesta es simple: tendría que haber sido siempre tratado como hombre. Por la suerte que asigna a sus miembros inactivos, la sociedad se desenmascara; siempre los ha considerado como material. Confiesa que para ella sólo cuenta el beneficio y que su "humanismo" es pura fachada [...] La sociedad sólo se preocupa por el individuo en la medida en la que le aporta", pp. 568-9.

${ }^{36}$ Véase Josef Pieper, De la divine folie, 2006, Gèneve, Ad Solem, trad. al francés por Maurice de Gandillac, revisado por Pierre Blanc.

${ }^{37}$ Véase Martin Heidegger, "Sérénité" en Questions III y IV, 1990, Paris, Gallimard, trad. al francés por André Préau, pp. 131-48. 
la una actitud de no dominio del mundo ni de sí, que permite abandonarse y relajarse, acoger al prójimo y a lo real en una actitud contemplativa. "En el ocio", precisa Josef Pieper, "lo que es verdaderamente humano está salvaguardado y conservado". ${ }^{38}$ El hecho de que existan actividades que tienen su fin en sí mismas es la manifestación tangible de lo que es el ser humano: un ser cuya dignidad no proviene del hecho de ser útil, de cumplir un papel y una función útil a la sociedad o de ejercer facultades personales, como la autonomía y la razón; al contrario, tiene un valor intrínseco por el simple hecho de ser un fin en sí mismo. De esa manera, la afirmación del amor lo confirma en una existencia y en el lugar indispensable que ocupa en el seno de la comunidad. ${ }^{39}$

La dignidad intrínseca se revela más clara y potentemente cuando el ser humano ya no "sirve" para nada, cuando se vuelve irreconocible y alicaído, cuando tiene la sensación de ser privado del sentimiento subjetivo de la dignidad, sumergido en un estado profundo de vulnerabilidad y dependencia. Esta dignidad intrínseca ya no puede sustentarse en la apariencia de la dignidad concedida por el papel y la función, por la decencia y el dominio de sí en el plano de la razón y de la voluntad. La dignidad intrínseca se desvela, entonces, en su pura desnudez y su presencia exige una respuesta por parte del otro y de la sociedad, con el fin de asegurarlo y de confirmarle que es un sujeto, que no está "de más" a pesar de su decadencia, que no es ni peso "muerto" ni un parásito, sino que su existencia es fantástica, que su presencia es un privilegio, en resumen, que posee un valor en sí, una dignidad

${ }^{38}$ Josef Pieper, Le Loisir, fondement de la culture, 2007, Genève, Ad Solem, trad. al francés por Pierre Blanc, pp. 49-50.

${ }^{39}$ Norberto Bobbio recalca, a la edad de 95 años y cuatro años antes de su muerte, que lo más importante no es la suma de esfuerzos destinados a conocer y dominar lo real, sino simplemente la relación con el prójimo: "He consagrado una gran parte de mi larga vida a leer y a estudiar una infinidad de libros y de documentos, utilizando incluso los momentos más pequeños del día, desde mi juventud, para 'no perder tiempo' [...]. Desde ahora, tengo la conciencia tranquila, tranquila pero infeliz por no haber llegado más que al pie del árbol del conocimiento. No he obtenido de mi trabajo las satisfacciones más durables de mi vida -no obstante los honores, los premios, el reconocimiento público que he recibido, con gratitud pero sin haberlos ni ambicionado ni buscado. Las satisfacciones más grandes las he obtenido de mi vida relacional, de los maestros que me han educado, de las personas que he amado y que me han amado, de todos aquellos que siempre han estado cerca de mí y que ahora me acompañan en la última parte del camino", op. cit., p. 151. 
intrínseca incluso cuando no será competente nunca más y a pesar de haber costado a la sociedad. La dignidad intrínseca afirma que uno no se puede deshacer del "problema" económico y social del "viejo viejo" simplemente eliminándolo. Lo que es indigno es tratar al "viejo viejo" como si hubiera perdido su dignidad intrínseca, considerar que la dignidad desaparece desde que se eclipsa el sentimiento de dignidad. Muy al contrario, la dignidad intrínseca existe previa a todo reconocimiento del prójimo, puesto que no es el prójimo quien concede una dignidad de este tipo; le corresponde en cambio, así como a la sociedad, ser testigo y demostrar ante el "viejo viejo" esta dignidad en lo que Levinas llama "una perspectiva ética del inter-humano", ${ }^{40} \mathrm{y}$ a pesar de la eventual pérdida del sentimiento subjetivo de la dignidad.

Es responsabilidad de la sociedad poner todo en marcha para recordar, sobre todo cuando el otro está desfalleciendo, que es todavía, y siempre, un fin en sí, portador de una dignidad que exige respeto, solicitud y compasión por parte del sano. El otro, decaído, lo interpela y le pide una respuesta responsable, la cual contribuye, entre otras cosas, a una perfección moral que realza la virtud. Desde este punto de vista, la perfección no realza la ilusión de la independencia; reside más profundamente, en la dimensión ética que requiere -precisa Emmanuel Levinas- "la perspectiva interhumana de $m i$ responsabilidad por el otro hombre, sin preocupación de reciprocidad, [es en mi] llamado a su auxilio gratuito, [es en] la asimetría de la relación de uno al otro". ${ }^{41}$ La mirada puesta sobre el prójimo y el compromiso responsable de sus aspectos no deben ser condicionados por las contingencias de la enfermedad, de la deficiencia, de la vulnerabilidad, del peso financiero, de lo útil.

Dicho de otra manera, es la realización de aquello a lo que el ser humano es llamado a implicarse, por ejemplo, la práctica de ciertas virtudes que se ejercen especialmente mediante el compromiso en favor de los más dependientes y de los más vulnerables de la comunidad humana. Es porque el "viejo viejo" posee una dignidad intrínseca que el saludable debe de responder; de esta manera, desarrolla ciertas virtudes.

${ }^{40}$ Emmanuel Levinas, "La souffrance inutile", Entre nous. Essais sur le penser-à-l'autre, 1991, Paris, Grasset, pp. 103.

${ }^{41}$ Ibid., p. 112. 
No es en razón del deseo de adquirir o desarrollar virtudes particulares que el sano debe respetar al "viejo viejo" e ir a su ayuda; esto volvería a concebir al "viejo viejo" como un medio, recibiendo una dignidad por procuración, como afirma Tristram Engelhardt. ${ }^{42}$ La dignidad intrínseca del "viejo viejo", como aquella de cada uno en nuestra sociedad, tan débil, dependiente, deficiente, nos recuerda en cierta forma la realidad de toda vida humana, nos hace cobrar conciencia de nuestra dignidad intrínseca, no subordinada al ejercicio competitivo de la razón y de la autonomía. Aceptando la fragilidad del otro, incluido aquel que es plenamente dependiente; reconociendo su dignidad intrínseca reconocemos, justamente, nuestra propia fragilidad y vulnerabilidad y, a fin de cuentas, nuestra propia dignidad. Un reconocimiento tal permite relativizar la exigencia tiránica de la autonomía (incluida la independencia) y del dominio, y aceptar nuestra propia dependencia radical, que no puede ser vivida sin la ayuda de la mirada del prójimo que atestigua sin cesar nuestra dignidad, confirmándonos en nuestra certeza de que no estamos nunca "de más". La aceptación de la vulnerabilidad humana está en el corazón de una ética del "cuidar", que reconoce en el "viejo viejo" no un simple organismo deficiente que hay que mantener, para quien proveeríamos únicamente una prestación de cuidados cuantificables sino más bien un cuerpo con una personalidad. Así, la comunidad de los sanos continúa construyendo una relación con esta persona frágil, en una reciprocidad que puede cobrar otra forma.

En tal reconocimiento, en tal habitación de la dependencia, de la no autonomía que se revelan en el "viejo viejo" o en el minusválido mental, puede desarrollarse una auténtica solidaridad, fundada en una dignidad humana opuesta a la exigencia tiránica del rendimiento y de la eficacia por la eficacia. Un mundo humano se caracteriza por el hecho de aceptar que el otro, igual que yo, puede vivir con sus límites y sus minusvalías personales; dicho de otra manera, el derecho de vivir no depende de la calidad de vida. "El bien común, es decir, la plenitud de la comunidad, no se puede vivir, precisa Thierry Collaud, salvo si todos los miembros tienen su lugar y ninguno es considerado como un

${ }^{42}$ Véase Tristram Engelhardt, The Foundations of Bioethics, 1996, Oxford, Oxford University Press, p. 147. 
estorbo", ${ }^{43}$ ni siquiera el "viejo viejo". O, por retomar las palabras de Pieper, “el 'bien común' supone, entre otros, la existencia de hombres consagrados a una vida improductiva, vuelta hacia la meditación". ${ }^{44}$

El "viejo viejo" nos enseña que lo esencial de una vida humana no reside únicamente en la dimensión de lo útil y de lo eficaz, sino también en la dependencia confiada hacia el prójimo. La persona frágil nos pone, como subraya MacIntyre, "en capacidad de enseñarnos algo esencial que consiste, para alguien más, en estar enteramente confiado a sus cuidados, con la finalidad de que respondamos por su bienestar". ${ }^{45}$ Cuidar del otro, particularmente de aquel que tiene el sentimiento subjetivo de ser privado de su dignidad, implica sentir empatía hacia él, compasión, considerándolo "con respeto, como un fin [en sí] y no una simple herramienta que se manipula para su propio beneficio", ${ }^{46}$ como afirma Martha Nussbaum al promover las artes liberales para formar al ciudadano del siglo XXI, en oposición a la predominancia de las artes serviles o útiles. La autonomía individual no puede desarrollarse más que en la medida en que incluya el reconocimiento de la dependencia fundamental de sí mismo y del prójimo, de la interdependencia o de lo "inter-humano", ${ }^{47}$ que constituye el corazón mismo de la existencia humana personal. El ser humano nunca se vuelve sólo un sujeto racional y autónomo: un acontecimiento o desempeño semejante sólo es posible con la ayuda del otro, a semejanza de la educación; es lo mismo con el ejercicio ordinario de las virtudes. "El reconocimiento de la dependencia es la clave de la independencia" o de la autonomía,

${ }^{43}$ Thierry Collaud y Concepción Gómez, Alzheimer et démence. Recontrer les malades et communiquer avec eux, 2010, Saint-Maurice, Ed. Saint-Augustin, pp. 71.

${ }^{44}$ Josef Pieper, Qu'est-ce que philosopher?, 2004, Le Mont-Pèlerin, Ediciones Raphaël, trad. al francés por Jean-Léon Muller, con un apéndice de T.S. Eliot, p. 11.

${ }^{45}$ Alasdair MacIntyre, Dependent Rational Animals. Why Human Beings Need the Virtues, 2008, Chicago-La Salle, Illinois, Open Court, pp. 135.

${ }^{46}$ Martha Nussbaum, op. cit., p. 25. Termina de esta manera su discurso en favor de las artes liberales: "Si no insistimos en la importancia crucial de las humanidades y las artes, éstas desaparecerán, porque no producen dinero. Pero ofrecen algo más preciado: un mundo donde vale la pena vivir, individuos capaces de ver a los otros seres humanos como personas con derecho propio, con pensamiento y emociones propias, que merecen respeto y simpatía, y países capaces de sobrepasar el miedo y el recelo en favor del debate empático y razonable", p. 179.

${ }^{47}$ Levinas, op. cit., p. 103. 
recalca MacIntyre. ${ }^{48}$ El ser humano no puede ser realmente autónomo, en el sentido de un sujeto moral virtuoso, salvo si acepta y toma la responsabilidad de ocuparse de los más dependientes, en particular de los "viejos viejos". Sin ser ya competente en absoluto, el "viejo viejo" resalta esta dimensión de la dignidad que afirma que el ser humano es un fin en sí mismo; las atenciones de los padres de niños discapacitados mentales son un ejemplo impresionante. "Los padres de personas muy discapacitadas son los paradigmas de la buena madre y del buen padre, mientras que presentan el modelo y la llave de la tarea de todos los padres". ${ }^{49}$

El “viejo viejo" también nos enseña la importancia de la capacidad de estar presente en el presente, cuya correspondencia serían las artes o las actividades cuyo fin radica en sí misma. El "viejo viejo" ocupa un tiempo que parece suspendido, desplazado en relación con la carrera desenfrenada por lo útil y eficaz, en la cual no se está muy presente, ni para sí ni para el prójimo, sino tendido hacia un porvenir donde el presente no tiene sentido más que en la medida en que es útil a lo que pasará. El "viejo viejo" enseña al sano, siempre apresurado por el tiempo, esta atención al instante, donde el amor es el modelo. Paul Claudel, a la edad de 84 años, dos años antes de morir, resume muy bien esta presencia en el instante: "Ayer, suspira uno. Mañana, suspira el otro. Pero hay que haber alcanzado la vejez para entender el sentido resplandeciente, absoluto, irrecusable, irremplazable de esta palabra: Hoy". ${ }^{50}$ Y François Mauriac apunta: "No me siento desligado de nada ni de nadie. Pero vivir me bastaría para ocuparme a partir de ahora. Esta sangre que afluye todavía en mi mano puesta sobre mi rodilla, este mar que siento latir dentro de mí, este reflujo y este flujo que no son eternos, este mundo

${ }^{48}$ MacIntyre, op. cit., p. 96.

${ }^{49} \mathrm{Ibid}$., p. 91 . Apunta más adelante: "Entonces cada uno de nosotros alcanza nuestro bien sólo si y en la medida exacta en que otros hacen nuestro bien como su bien propio, viniendo a nuestro auxilio durante los períodos de incapacidad, ayudándonos a volvernos nosotros mismos; este tipo de seres humanos - por adquisición y el ejercicio de las virtudes-que hacen del bien de los otros su propio bien (y esto sin haber calculado que sólo ayudando a los otros nos ayudarán, una suerte de trueque de una ventaja por otra ventaja)", p. 108.

${ }^{50}$ Paul Claudel, Journal, vol. II (1933-1955), 1969, Paris, Gallimard, Pléiade, cuaderno X, agosto-septiembre 1952, p. 818. 
tan listo a terminarse exige una atención en todos los instantes, de todos estos últimos instantes antes del último: la vejez es eso". ${ }^{51}$ El "viejo viejo" nos invita a probar otra vez y a reinvertir el presente en una actitud de acogida del tiempo, caracterizada no por su dominio, sino por su paciencia ante sí mismo y ante el prójimo, lo que expresa de maravilla el amor entendido como presencia paciente hacia el prójimo.

La humanización de una sociedad se mide, en cierta manera, en la forma en la que cuida de los "viejos viejos". ${ }^{52}$ La realización de la persona en la vivencia cotidiana del cuidado otorgado a seres humanos vulnerables y deficientes contribuye a la plenitud de una auténtica cultura, que mira por el bien común de la comunidad humana. Ese bien común resalta la autoridad de la dignidad intrínseca del ser humano, más allá de su desempeño - que manifiestan en efecto su cumplimiento, pero en absoluto su valor-y de los intereses y deseos de los individuos. El compromiso moral en favor de los más vulnerables contribuye al bien común y a una auténtica cultura humanista. Cuando el orden se invierte, cuando lo útil se convierte en el criterio y se constituye como el fin de la existencia personal o, para decirlo con Jürgen Habermas, cuando se tiende a "la abrasión de nuestra sensibilidad moral en beneficio de un cálculo de los costos y beneficios", ${ }^{53}$ entonces el ser humano no puede cumplirse y la cultura muere. La cultura, caracterizada por el ocio, es lo que le permite al "hombre permanecer siendo hombre", ${ }^{44}$ retomando la reivindicación de Simone de Beauvoir en relación con los "viejos viejos". 55

${ }^{51}$ Mauriac, op. cit., p. 419.

${ }^{52}$ Alasdair MacIntyre apunta que la "plenitud individual" de los seres humanos deficientes, minusválidos, dependientes, "es un indicio imporante de la plenitud de toda la comunidad", op. cit., p. 109.

${ }^{53}$ Jürgen Habermas, L'Avenir de la nature humaine. Vers un eugénisme libéral? 2002, Paris, Gallimard, trad. al francés por Christian Bouchindhomme, pp. 36-7.

${ }^{54}$ De Beauvoir, op. cit., p. 568.

${ }^{55}$ Martin Pohl, director del departamento de física nuclear y de partículas en la Universidad de Ginebra, contesta a la pregunta de un periodista en relación con el tema de la rentabilidad y de la utilidad del LHC del Cern en Ginebra, que cuesta diez mil millones de francos por año: "forma parte de la cultura humana el hacer preguntas [como] el funcionamiento de la materia, de la naturaleza de la energía, el funcionamiento del universo. Es una cuestión cultural. [...] No me gustaría vivir en una ciudad que no se toma la molestia de la búsqueda fundamental, así como no me gustaría vivir en una ciudad que no tenga una ópera que valga la pena". Y el periodista concluye: "Finalmente el LHC es tan importante como la ópera"; podríamos añadir "y que 
"Una cultura verdadera no puede realizarse más que en el terreno del ocio", ${ }^{56}$ de actividades que no sirven para nada y cuya presencia nos recuerda lo que es el ser humano, en lo más profundo de sí mismo: el poseedor de una dignidad que escapa a todo fin útil, a toda reflexión funcional y cuantitativa, a los intereses y a los deseos de los sanos. "Cuidar" del "viejo viejo" es afirmar que no está nunca "de más"; es darle a redescubrir su dignidad intrínseca cuando ha perdido el sentimiento subjetivo de su dignidad; es confirmarlo en su ser al comunicarle que es simplemente fantástico que sea y que continúe siendo. La vejez es una etapa natural de la vida humana que se atraviesa en presencia del prójimo, como el nacimiento. Cuidar del "viejo viejo" está en el corazón de una sociedad humanista, de una política humanista. El precio a pagar por una cultura así, claro, será siempre "demasiado caro".

el viejo viejo". Véase Radio Suisse Romande, lunes 16 de enero de 2012, “L'invité de la rédaction" a las 7. 38 .

${ }^{56}$ Josef Pieper, “Muße und menschliche Existenz”, Werke, 2008, vol. 8.2, p. 456. 